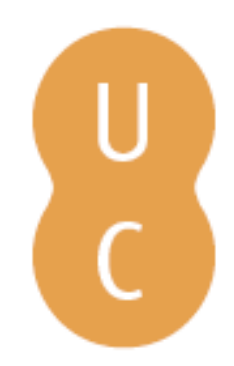

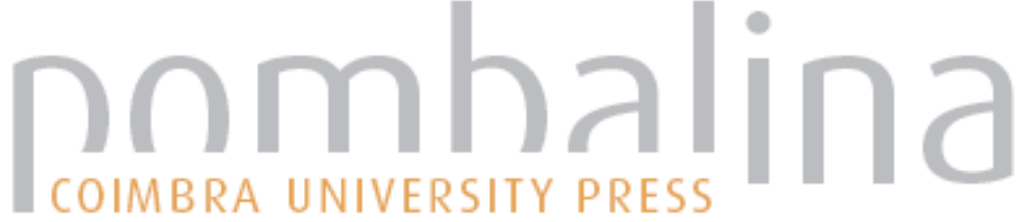

\section{Releitura de Althusser: o teatro no centro da teoria}

\author{
Autor(es): $\quad$ Pita, António Pedro
}

Publicado por: Imprensa da Universidade de Coimbra

URL

persistente: URI:http://hdl.handle.net/10316.2/31568

DOI: $\quad$ DOI:http://dx.doi.org/10.14195/978-989-26-0199-1_1

Accessed : $\quad$ 26-Apr-2023 12:07:29

A navegação consulta e descarregamento dos títulos inseridos nas Bibliotecas Digitais UC Digitalis, UC Pombalina e UC Impactum, pressupõem a aceitação plena e sem reservas dos Termos e Condições de Uso destas Bibliotecas Digitais, disponíveis em https://digitalis.uc.pt/pt-pt/termos.

Conforme exposto nos referidos Termos e Condições de Uso, o descarregamento de títulos de acesso restrito requer uma licença válida de autorização devendo o utilizador aceder ao(s) documento(s) a partir de um endereço de IP da instituição detentora da supramencionada licença.

Ao utilizador é apenas permitido o descarregamento para uso pessoal, pelo que o emprego do(s) título(s) descarregado(s) para outro fim, designadamente comercial, carece de autorização do respetivo autor ou editor da obra.

Na medida em que todas as obras da UC Digitalis se encontram protegidas pelo Código do Direito de Autor e Direitos Conexos e demais legislação aplicável, toda a cópia, parcial ou total, deste documento, nos casos em que é legalmente admitida, deverá conter ou fazer-se acompanhar por este aviso.

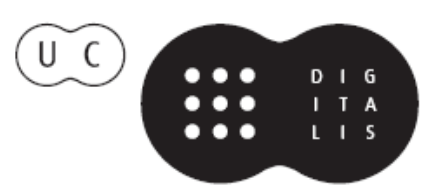


Maria Manuela Tavares Ribeiro

Coordenação

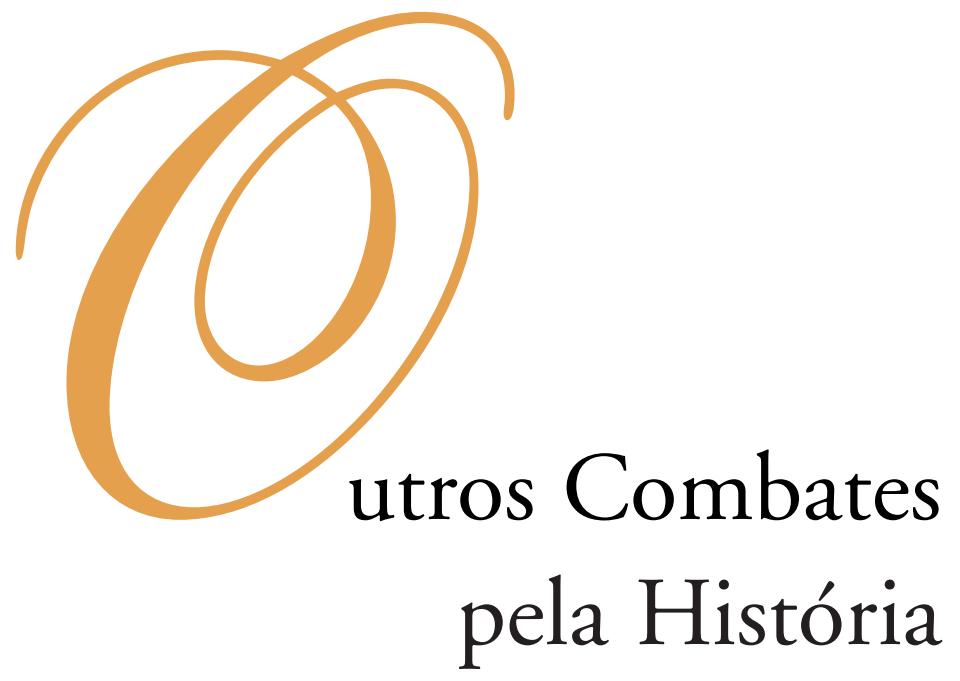




\section{COORDENAÇĀO EDITORIAL}

Imprensa da Universidade de Coimbra

Email: imprensauc@ci.uc.pt

URL: http://www.uc.pt/imprensa_uc

Vendas online: http://livrariadaimprensa.com

\section{CONCEPÇÃO GRÁFICA}

António Barros

\section{ORgANIZAÇĀO DOS TEXTOS}

Isabel Maria Luciano

Marlene Taveira

PRÉ-IMPRESSÃO

António Resende

Imprensa da Universidade de Coimbra

EXECUÇÃO GRÁFICA

SerSilito • Maia

ISBN

978-989-26-0041-3

DEPósito LEGAL

OBRA PUBLICADA COM O APOIO DE:

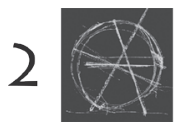

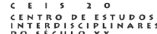

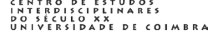

FCT Fundação para a Ciência e a Tecnologia

MINISTÉRIO DA CIÊNCIA, TECNOLOGIA E ENSINO SUPERIOR Portugal

Programa Operacional Ciência, Tecnologia, INOVAÇĀo DO QUADRo COMUNITÁRIO DE APOIO III

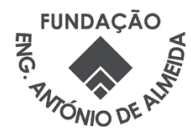

C JULHO 2010, IMPRENSA DA UNIVERSIDADE DE COIMBRA 
Maria Manuela Tavares Ribeiro

Coordenação

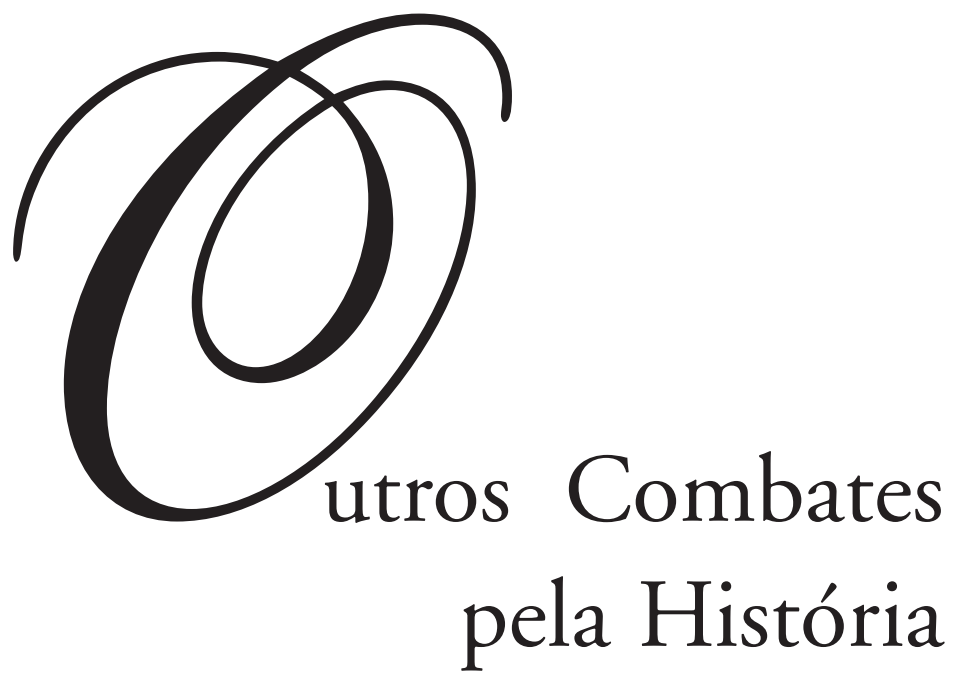

- colmbra 2010 
Outras Teorias da História 


\section{António Pedro Pita}

\section{Releitura De Althusser: O TEATRO NO CENTRO DA TEORIA}

Não fui aluno do Doutor Luís Reis Torgal. Mas frequentei episodicamente as suas aulas, uma delas ocupada com referência desenvolvida à obra de Sílvio Lima, $O$ determinismo, o acaso e a previsão na História (Coimbra, 1943).

Foi casual o encontro com o texto de Sílvio Lima. Mas foi premeditada a procura na História (e não, por exemplo, na Psicologia) de uma chave que permitisse situar e agir ${ }^{1}$.

Será presunção ou excesso ou ignorância sugerir que tudo se passou como se, de repente, a história se tivesse tornado transparente e nós víssemos como é o movimento da história, subitamente concentrada no modo do presente e tornada a cena ilimitadamente aberta das nossas mais fundas expectativas?

Em jeito de contraponto eufórico da tragédia chilena, o 25 de Abril reforçou não só as razões do nosso optimismo histórico mas, muito mais do que isso, as razões da história como optimismo.

A melancolia virá mais tarde: no plano filosófico (porque há outros, não menos importantes) alimentada sobretudo por Verdade e Método, a obra prima de Hans-Georg Gadamer ${ }^{2}$.

Mas pelos anos de 1975-76, o imperativo existencial consistia em dar solidez conceptual ao optimismo que cruzava a cena da história como luz sem sombras nem fantasmas.

No meio universitário, pelo menos nesta Universidade de Coimbra, entre a Filosofia e a História, a obra de Louis Althusser desempenhou um papel considerável.

Já conhecido entre nós ${ }^{3}$, o Althusser de Pour Marx e de Lire le Capital recoloca-se no centro do debate político-filosófico, nestas circunstâncias não de todo alheio à

\footnotetext{
${ }^{1}$ É o primeiro momento de uma releitura global da obra de Louis Althusser, em curso. O texto agora publicado mantém as dimensões e o tom da comunicação.

${ }^{2} \mathrm{O}$ traço dessa leitura e suas consequências encontra-se em «Problema do sujeito, eficácia da história e experiência hermenêutica» in AAVV, Tradição e Crise - I, Faculdade de Letras, Coimbra, 1986, pp. 414-468.

3 Embora este artigo não pretenda ser um ponto de situação da presença da obra de Louis Althusser em Portugal, importa referir a edição portuguesa de alguns dos seus textos clássicos: Lenine e a filosofia, Editorial Estampa, Lisboa, 1970; Sobre o trabalho teórico, Editorial Presença, Lisboa, s/d; Montesquieu, a política e a história, Editorial Presença, Lisboa, 1972; Resposta a John Lewis, Editorial Estampa, Lisboa, 1973;
} 
oscilação entre a hipótese de elaboração de uma verdadeiro marxismo (simultaneamente limpo da ganga humanista e da herança estalinista) e o reforço da convicção da profunda heterogeneidade do marxismo.

Por outras palavras, os artigos reunidos em Pour Marx (onde encontramos as primeiras configuraçôes de um projecto filosófico e seus dispositivos metodológicos, entre os quais importa lembrar a demarcação entre o Marx da juventude e o Marx da maturidade, o conceito de sobredeterminação e a noção do marxismo como anti-humanismo teórico) já foram lidos em conjugação polémica mas necessária com toda a produção posterior, mesmo com aquela que os infirma, contradita ou dissolve.

Não é, todavia, nos protocolos de leitura de Pour Marx nem na análise dos efeitos políticos e filosóficos dessa leitura que incide a presente comunicação. Pretendo limitar-me a um texto que resistiu incólume a essa ofensiva interpretativa, um texto não lido ou cuja leitura praticamente não deixou rasto.

1. O texto em questão intitula-se “"O Piccolo”, Bertolazzi e Brecht (Notas sobre um teatro materialista)» ${ }^{4}$.

O Piccolo Teatro de Milão trouxe ao parisiense Teatro das Nações, em Junho de $1962^{5}$, a peça El Nost Milan de Carlo Bertolazzi, com encenação de Giorgio Strehler.

Althusser assiste ao espectáculo, que teve, aliás, uma péssima recepção crítica. Ainda em Junho inicia o seu texto, que conclui no mês seguinte.

No seu artigo, Louis Althusser passa rapidamente da peça (ou melhor: da representação, quero dizer, da peça de Bertolazzi encenada por Strehler) para a História.

No enredo da peça e no modo como ela ocorre, concretamente, no espaço cénico, nas soluções técnicas adoptadas pelo encenador, Louis Althusser lê os princípios dinâmicos do espectáculo, interpreta o espectáculo e, ao mesmo tempo, lê a peça não só como representação de um texto mas como representação do mundo.

Onde funda Althusser a legitimidade de uma tal operação? E: porque é que o espectáculo não é simplesmente um espectáculo, que começa no princípio e acaba no fim?

Ideologia e aparelhos ideológicos do estado, Editorial Presença, Lisboa, 1974; Sobre o Contrato Social, Iniciativas Editoriais, Lisboa, 1976; Posiçôes, Livros Horizonte, Lisboa, 1977; "Comunismo, estado e sociedade de transição", L. Althusser entrevistado por Rossana Rossanda, in Abril, n. o 4, Maio. 1978, pp. 25-32. A conferência A transformação da filosofia, pronunciada em Granada em 1976, importantíssima pelas novas perspectivas que abre, publicada pela Editorial Estampa, Lisboa em 1981, foi conhecida entre nós logo em 1976, através da edição da Universidade de Granada. (Cf.: António Pedro Pita, «Para uma prática marxista da filosofia (sobre A transformação da filosofia de Louis Althusser)» in Seara Nova, n. ${ }^{\circ}$ 1582, 1977.) Em Estruturalismo - antologia de textos teóricos (Portugália Editora, Lisboa, 1967), Eduardo Prado Coelho recolheu os textos «Freud e Lacan» (pp. 229-255) e, extraído de Lire le Capital, "A imensa revolução teórica de Marx" (pp. 289-308). O volume Polémica sobre o Humanismo (Editorial Presença, Lisboa, s/d) é uma recolha de textos fundamentais, e alguns pouco acessíveis, directamente relacionados com a controvérsia provocada pelas teses de Althusser sobre o humanismo. Visões de conjunto: João Esteves da Silva, Para uma teoria da história - de Althusser a Marx, Diabril, Lisboa vol. 1: 1975 e vol. 2: 1976; Acílio da Silva Estanqueiro Rocha, Problemática do estruturalismo, INIC, Lisboa, 1988 (centrada na obra de Claude Lévi-Strauss).

${ }^{4}$ Louis Althusser, "O «Piccolo», Bertolazzi e Brecht (Notas sobre um teatro materialista)», in Pour Marx (1965) François Maspero, Paris, pp. 129-152.

${ }^{5}$ Para reconstituir as condiçōes biográficas, cf: L. Althusser, Lettres à Franca (1961-1973), Stock/IMEC, Paris, p. 182 (carta de 15. Junho. 62) - 186. 
O pressuposto de Althusser é simples: «o que permite a existência do teatro é que o público vem ver na cena o que tem na cabeça e no corpo. Para retomar uma velha fórmula, que não é falsa, no teatro o que o público vem ver é ele próprio" ${ }^{6}$.

2. O teatro é uma cena da História. Em algum teatro, o dramaturgo e o encenador (e por vezes também os actores) fazem o possível para que tudo ocorra como se a História estivesse a mostrar-se a si mesma. Ocultam os procedimentos técnicos que constituem a mediação. Provocam e alimentam no espectador o processo de reconhecimento.

Mas há outro teatro: aquele que não quer ser a História mostrando-se a si mesma mas quer mostrar o movimento da História: permite que nós vejamos (e saibamos) o que nenhum dos personagens tem condiçôes para ver e saber; e coloca resistências à operação de reconhecimento.

3. Na peça de Bertolazzi encenada por Giorgio Strehler encontra Louis Althusser os elementos de um "teatro materialista» (expressão utilizada no título) ou de uma prática materialista do teatro - mas sobretudo as categorias centrais de uma prática marxista da filosofia.

O texto em análise não é, pois, "uma pausa, uma escapada do universo denso dos conceitos da filosofia, do materialismo histórico e da economia política» 7 .

É o "verdadeiro centro geométrico e teórico» ${ }^{8}$ de Pour Marx, como poderá concluir-se esquematicamente mesmo nesta breve comunicação.

Em primeiro lugar, a peça põe em cena tempos que não são homogéneos: um "tempo vazio, longo e lento a viver» coexiste mas sem nenhuma relação com um "tempo pleno, como um relâmpago"; um «espaço povoado de uma multidão de personagens com relações mútuas acidentais ou episódicas» coexiste, mas sem nenhuma relação, com um espaço curto, constituído como conflito ou como drama?.

Pode dizer-se que a cena da história está esgaçada. Mas a questão principal é perceber em que condições é que pode formar-se uma consciência unificadora, ou melhor: sob que condiçôes (poderíamos dizer: na trama de que mediações) a fragmentação da sociedade e da história pode ser unificada na consciência? Althusser anota a grande importância do teatro: mostra que a consciência espontânea é imediatamente unificadora e totalizante - e, por isso mesmo, ilusória.

Segundo aspecto. No teatro, em algum teatro, captamos a odisseia e o naufrágio da consciência: o que vemos - o personagem construindo a clareza do seu conhecimento no interior de uma espécie de cegueira profunda - é o inconsciente no seu trabalho. Ora, trazida pela encenação de um Giorgio Strehler leitor de Brecht para um contexto estético-filosófico que não era o seu, a peça de Bertolazzi mostra que é indispensável "uma crítica da ideologia espontânea em que vivem os homens»; que «nenhuma

${ }^{6}$ L. Althusser, «Sur Brecht et Marx» (1968) in Ecrits philosophiques et politiques, t. II, Stock/IMEC, Paris, p. 554.

7 Marc-Vincent Howlett, "Le théâtre n'est-il pour Althusser qu'un risqué "fictif”?» in AAVV, Lire Althusser aujourd'hui, L'Harmattan/Futur Antérieur, Paris, 1997, p. 116.

8 E. Balibar, «Avant propos pour la réédition de 1996» de Pour Marx, La Découverte, Paris, 1996, p. VIII.

${ }^{9}$ L. Althusser, ibidem, p. 134. 
personagem acolhe em si numa forma reflectida a totalidade das condições do drama» ${ }^{10}$ e que a ideologia de uma sociedade ou de um tempo é «a consciência de si dessa sociedade ou desse tempo, quer dizer, uma matéria imediata que implica, procura e naturalmente encontra espontaneamente a sua forma na consciência de si que vive a totalidade do seu mundo na transparência dos seus próprios mitos» ${ }^{11}$.

A crítica da autoconsciência ou da consciência de si é, pois, unicamente, o aspecto mais imediato de uma crítica mais ampla, a crítica da consciência como ilusão - cujo primeiro momento é a convicção de ser original e originária.

Ora, não é pela consciência que começa a nossa relação com o mundo nem é pela dialéctica da consciência que se chega ao conhecimento do real. A consciência «acede ao real não pelo desenvolvimento interno mas pela descoberta radical do outro diferente de si» 12 .

Por conseguinte, nenhum personagem é, em si mesmo, a moral da história salvo quando avança para a ribalta, tira a máscara e, terminada a peça, extrai a lição dela: quer dizer, quando se coloca, de certo modo, no lugar do espectador.

Levar a sério a centralidade deste texto significará expandir o alcance de qualquer dos textos que o rodeiam e da estratégia em acto em toda a obra: dos textos que o precedem e para ele confluem porque o tema, aí, é o das condições filosóficas que ainda não permitem compreender a consciência, enquanto auto-consciência, como ilusão; dos textos que se lhe seguem porque são aqueles que definiram progressivamente o descentramento da consciência. Mas também da estratégia geral da obra, que só por desatenção pode continuar a ser confundida com uma recolha de ensaios e em cuja tessitura cerrada Etienne Balibar reconhece três constelações: uma organizada em torno do conceito de corte epistemológico; outra, organizada em torno do conceito de estrutura; a terceira, organizada em torno do conceito de ideologia.

Sublinhe-se: qualquer uma destas constelações é uma determinação específica do lugar da consciência.

4. Lidos hoje, no contexto mais amplo de uma obra terminada e interminável, os textos de Pour Marx são menos o enunciado de uma tese do que a sistematização regional de uma problemática mais ampla da qual estudos fragmentários foram dando conhecimento parcelar: sobre a ideologia, sobre a filosofia como prática destotalizadora, sobre a irredutibilidade do materialismo histórico às categorias constituintes das filosofias da história.

Como se a História devesse ser pensada entre a necessidade e a contingência, entre a homologia do ser e do pensar e o primado do ser sobre o pensar.

Belo tema para uma nova releitura de $O$ determinismo, o acaso e a previsão na História de Sílvio Lima.

Alguns dos novos combates serão, por certo, os que libertam o tempo e o espaço da ordem da homogeneidade, o passado da teleologia, o futuro da determinação e afirmam o presente como um por-vir sempre eminente, em trânsito de heranças múltiplas.

\footnotetext{
10 Idem, ibidem, p. 143.

${ }^{11}$ Idem, ibidem, pp. 144-5.

12 Idem, ibidem, p. 143.
} 

Série

Documentos

Imprensa da Universidade de Coimbra

Coimbra University Press

2010

- U

C • 